\title{
Agricultural Workers
}

National Cancer Institute

\section{Source}

National Cancer Institute. Agricultural Workers. NCI Thesaurus. Code C122421.

Workers who maintain the quality of farms, crops, and livestock by operating machinery and doing physical labor under the supervision of farmers, ranchers, and other agricultural managers. 